\title{
KNOWLEDGE OF ALZHEIMER'S DISEASE AND TRAINING NEEDS IN FINAL YEAR MEDICAL AND PHARMACY STUDENTS
}

\author{
C. Scerri
}

\begin{abstract}
Although a significant number of medical and pharmacy professionals come into contact with an increasing number of individuals with Alzheimer's disease and other dementias, there is concern on the lack of knowledge and skills received during their undergraduate training programmes with the consequence of not providing the required hospital and community care for these individuals following programme completion. The aim of this report is to describe the results of a small scale study investigating the level of knowledge of Alzheimer's disease and training needs in medical and pharmacy students at the end of their final year of undergraduate training. The findings indicated a lack of in-depth knowledge for both categories of students, in particular on risk factors and pharmacotherapeutic management highlighting an urgent need of refining existent training programmes that equip future medical and pharmacy professionals with the necessary skills in providing adequate care and management for individuals with the disease.
\end{abstract}

Key words: Alzheimer's disease, dementia, medical students, pharmacy students, knowledge.

\section{Introduction}

Alzheimer's disease (AD) is the most common form of dementia accounting to $50-70 \%$ of all the cases (1). In 2015 , it was estimated that $1.5 \%$ of the population in Malta had dementia, a figure that is projected to more than double in the next 30 years (2). This, in conjunction with the changing demographics favouring a progressive increase in the elderly population, will invariably put greater demands and challenges on medical and pharmacy professionals who, in the majority of cases, are at the forefront in providing formal care to these individuals both in hospital and the community. Concerns however exist that such healthcare professionals do not possess the required knowledge and skills to offer the required care and advice to these patients and their caregivers (3) with shortcomings in undergraduate curricula being one of the main reasons $(4,5)$. Such knowledge gaps were recently highlighted by general practitioners working in Malta as a motive towards their lack of understanding of dementia diagnosis and pharmacotherapeutic management of the cognitive and behavioural symptoms in individuals with dementia (6).

Department of Pathology, Faculty of Medicine and Surgery, University of Malta, Msida, Malta MSD 2080.

Corresponding Author: Charles Scerri Ph.D., Department of Pathology, Faculty of Medicine and Surgery, University of Malta, Msida MSD 2080, Malta; Tel.: +356 23402905; Fax: +356 21320281; E-mail: charles.scerri@um.edu.mt

Received August 12, 2016

Accepted for publication August 16, 2016
The aim of this study was to investigate the level of knowledge of $\mathrm{AD}$, including its pharmacotherapeutic management, and training needs in final year medical and pharmacy undergraduate students. The scope was to use the information gathered to support evidence on the need of enhancing dementia training in the current medical and pharmacy undergraduate curriculum in Malta with the latter being one of the priorites highlighted in the recent launch of the national dementia strategy (7).

\section{Method}

The targeted population consisted of all full-time undergraduate medical (MD) and pharmacy (BPharm) students in the final year of their studies at the University of Malta, the latter being the sole higher education institution licensed to offer tertiary education in both medicine and pharmacy. The Maltese medical degree programme is a five-year university course organised by the Faculty of Medicine and Surgery. Dementiaspecific topics are covered in teaching modules under the specialties of neurology, geriatric medicine, pharmacology and principles of good practice and psychological and social aspects of healthcare for a total of five hours throughout the whole training course. The Maltese undergraduate pharmacy 4-year programme is also organised by the Faculty of Medicine and Surgery with dementia training being delivered in a three-hour session focusing mainly on neuropathology, prevalence 
Table 1

Socio-demographic data, ADKS and ADPM scores of final year undergraduate medical and pharmacy students

\begin{tabular}{|c|c|c|c|c|c|c|}
\hline \multirow[b]{2}{*}{ Variables } & \multicolumn{2}{|c|}{$\operatorname{MD}(\mathrm{N}=82)$} & \multicolumn{2}{|c|}{ BPharm $(\mathrm{N}=39)$} & \multirow{2}{*}{$\begin{array}{l}\text { p-value } \\
\text { (MD vs. BPharm) }\end{array}$} & \multirow{2}{*}{$\begin{array}{l}\text { p-value } \\
\text { (vs. socio-demographics) }\end{array}$} \\
\hline & n $(\%)$ & Mean \pm SD & n $(\%)$ & Mean \pm SD & & \\
\hline \multicolumn{7}{|l|}{ Socio-demographic } \\
\hline \multicolumn{7}{|l|}{ Gender } \\
\hline Male & $38(46.3)$ & & $7(18.0)$ & & & \\
\hline Female & $44(53.7)$ & & $32(82.0)$ & & & \\
\hline Age (years) & & $22.4 \pm 2.19$ & & $21.7 \pm 1.48$ & & \\
\hline \multicolumn{7}{|c|}{ Having a family member with dementia } \\
\hline Yes & $12(14.6)$ & & $7(17.9)$ & & & \\
\hline No & $70(85.4)$ & & $32(82.1)$ & & & \\
\hline \multicolumn{7}{|c|}{ Caring for a family member with dementia } \\
\hline Yes & $3(3.7)$ & & $4(10.3)$ & & & \\
\hline No & $79(96.3)$ & & $35(89.7)$ & & & \\
\hline \multicolumn{7}{|c|}{ Clinical placement with dementia patients } \\
\hline Yes & $43(52.4)$ & & $21(53.8)$ & & & \\
\hline No & $39(47.6)$ & & $18(46.2)$ & & & \\
\hline \multicolumn{7}{|l|}{ Percentage correct scores } \\
\hline ADKS & & $77.85 \pm 9.78$ & & $72.82 \pm 9.72$ & 0.009 & \\
\hline Assessment and diagnosis & & $91.77 \pm 15.74$ & & $82.69 \pm 19.15$ & 0.003 & \\
\hline Risk factors & & $64.02 \pm 19.33$ & & $48.29 \pm 21.56$ & $<0.001$ & 0.040 (clinical placement -BPharm) \\
\hline Course of disease & & $77.74 \pm 22.57$ & & $82.69 \pm 19.16$ & & \\
\hline Life impact & & $82.93 \pm 20.45$ & & $81.20 \pm 19.93$ & & \\
\hline Treatment and management & & $86.59 \pm 16.76$ & & $83.33 \pm 15.53$ & & 0.028 (clinical placement -BPharm) \\
\hline Symptoms & & $78.96 \pm 20.21$ & & $82.69 \pm 21.58$ & & 0.037 (clinical placement -BPharm) \\
\hline Caregiving & & $72.44 \pm 18.23$ & & $65.13 \pm 24.16$ & & 0.025 (family member with dementia-MD) \\
\hline ADPM & & $65.58 \pm 11.63$ & & $69.81 \pm 10.49$ & & \\
\hline
\end{tabular}

ADKS: Alzheimer's Disease Knowledge Scale, ADPM: Alzheimer's Disease Pharmacotherapy Measure, BPharm: pharmacy students, MD: medical students

and pharmacotherapy.

The study consisted of a survey, in English language, composed of an anonymous closed-ended questionnaire and distributed to the students following the completion of all taught and clinical placement modules but prior to sitting for final assessment. The measurement tools included the Alzheimer's Disease Knowledge Scale (ADKS) (8) and the Alzheimer's Disease Pharmacotherapy Measure (ADPM). ADKS contains 30 true/false items aimed to assess knowledge on AD. It is designed to be used by healthcare professionals, students, patients, caregivers and laypeople to pinpoint educational needs (8). The questions focus on 7 subscales that characterise knowledge about $\mathrm{AD}$ namely on: risk factors, assessment and diagnosis, symptoms, course of the disease, life impact, caregiving, and treatment. The percentage correct score is calculated using the equation: sum of correct items / $30 \times 100$. The ADPM was developed by the author. It consists of 18 true/false items focusing on knowledge about pharmacological management in AD including available treatment options, role of supplementation, drug efficacy, dose titration, adverse effects, augmentation therapy and the use of antipsychotics for the behavioural and psychological symptoms of dementia (BPSD). Face validity was ascertained by asking three local clinical medical specialists in the field of dementia to independently evaluate the relevance of the topics selected. Similar to ADKS, the percentage correct score for ADPM was found by calculating the percentage of dividing the number of correct items by the maximum possible score.

The survey also contained a section that requested participants to rate their educational and training needs using a 3-point Likert scale (ranging from 1: least, 2: moderately and, 3: most needed) from a list of 20 topics related to the care of individuals with $\mathrm{AD}$ and related dementias (9).

Background characteristics of participating students were collected via closed-ended questions that looked for information about age, gender, presence of and/or caring for a family member with dementia, and history of caring for persons with dementia during clinical placement. The study was approved by the Faculty of Medicine and Surgery Ethics Committee as well as the Research Ethics 
Table 2

Perceived educational and training needs of final year undergraduate medical and pharmacy students

\begin{tabular}{|c|c|c|c|}
\hline \multirow[t]{2}{*}{ Educational needs and training } & \multirow{2}{*}{$\begin{array}{l}\text { MD } \\
\text { Mean } \pm \text { SD }\end{array}$} & \multicolumn{2}{|l|}{ BPharm } \\
\hline & & Mean \pm SD & p-value \\
\hline Understanding the medical aspects of ADRD (e.g. types and risk factors) & $2.52 \pm 0.61$ & $2.49 \pm 0.64$ & \\
\hline Understanding the principles of person-centred care & $2.46 \pm 0.61$ & $2.64 \pm 0.63$ & \\
\hline Dealing with challenging (e.g. aggressive) behaviour & $2.63 \pm 0.58$ & $2.77 \pm 0.48$ & \\
\hline How to recognise and treat excess disability (e.g. pain, constipation and incontinence) & $2.48 \pm 0.57$ & $2.59 \pm 0.59$ & \\
\hline How to deal with ethical issues related to ADRD & $2.34 \pm 0.65$ & $2.49 \pm 0.60$ & \\
\hline How to involve patients with dementia and their carers in decisions on care and treatment & $2.32 \pm 0.68$ & $2.64 \pm 0.54$ & 0.012 \\
\hline How to promote interprofessional teamwork in the management of patients with ADRD & $2.21 \pm 0.72$ & $2.62 \pm 0.54$ & 0.003 \\
\hline How to disclose ADRD to patients and carers & $2.30 \pm 0.66$ & $2.38 \pm 0.63$ & \\
\hline The use of technology in ADRD & $2.15 \pm 0.65$ & $2.33 \pm 0.58$ & \\
\hline Services that promote the well-being of patients with ADRD and their carers & $2.29 \pm 0.62$ & $2.49 \pm 0.56$ & \\
\hline Pharmacological treatment in ADRD & $2.54 \pm 0.69$ & $2.59 \pm 0.64$ & \\
\hline Psychosocial interventions in ADRD & $2.44 \pm 0.67$ & $2.56 \pm 0.55$ & \\
\hline How to maintain adequate nutritional status in patients with ADRD & $2.37 \pm 0.62$ & $2.51 \pm 0.60$ & \\
\hline How to care for patients with ADRD at the end-of life & $2.44 \pm 0.61$ & $2.64 \pm 0.54$ & \\
\hline
\end{tabular}

ADRD: Alzheimer's disease and related dementias

Committee of the University of Malta.

Descriptive statistics including mean data, standard deviations and percentages were used to describe sociodemographic data and the ADKS and ADPM scores. Following data analysis for normality of distribution by the Shapiro-Wilk test, the parametric independent sample t-test and the non-parametric Mann-Whitney $U$ test were used for group comparisons. Mean data was expressed as mean \pm SD (standard deviation). The significance level was set at 0.05 . All statistical analyses were performed using PASW Statistics (Version 20).

\section{Results}

A total of 82 medical ( $74.6 \%$ response rate) and 39 pharmacy (92.9\% response rate) final year students replied to the questionnaire with the female gender being over represented in the pharmacy but not the medical programme. The majority of respondents indicated that they don't have or care for a family member with dementia. Approximately half of the students in both programmes attended optional clinical placements with $\mathrm{AD}$ and related dementias patients (Table 1).

Students who attended the medical programme had significantly higher percentage of correct ADKS scores compared to pharmacy students $(\mathrm{t}=2.647, \mathrm{P}=0.009)$.
Moreover, analysis of the ADKS subscales revealed that medical students were more knowledgeable in assessment and diagnosis $(\mathrm{z}$-score $=-2.987, \mathrm{p}=0.003)$ and risk factors ( $\mathrm{z}$-score $=-3.712, \mathrm{p}<0.001)$ for AD. BPharm students who reported to have had exposure to dementia patients during their clinical placements had significantly higher scores in knowledge of risk factors ( $\mathrm{z}$-score $=-2.041, p=0.040)$, treatment and management $(\mathrm{z}$-score $=-2.194, \mathrm{p}=0.028)$ and symptoms $(\mathrm{z}$-score $=$ -2.091, $\mathrm{p}=0.037$ ) than their counterparts who did not have such exposure. A significant effect on the caregiving construct of the ADKS was reported in MD students having a family member with dementia ( $\mathrm{z}$-score $=-2.241$, $\mathrm{p}=0.025)$ and in BPharm students caring for a family member with dementia ( $\mathrm{z}$-score $=-2.036, \mathrm{p}=0.041$ ). No significant differences were reported in the percentage correct ADPM scores between the two undergraduate training programmes (Table 1).

The mean scores in all educational and training needs topics were greater than 2 indicating that the majority of students in both undergraduate programme categories necessitate more knowledge in these subject areas. Compared to BPharm students, MD students expressed a greater need of having more training in recognising a patient with $\mathrm{AD}$ and related dementias and how to distinguish such medical conditions from 
others ( $\mathrm{z}$-score $=-2.232, \mathrm{p}=0.026$ ). Conversely, BPharm students scored significantly higher in educational and training needs involving the use of physical restraint and sedation ( $\mathrm{z}$-scores $=-2.906, \mathrm{p}=0.004)$, the involvement of patients with dementia and their caregivers in decision taking on care and treatment $(\mathrm{z}$-score $=-2.514, \mathrm{p}=$ 0.012 ), and how to promote interprofessional teamwork in managing patients with $\mathrm{AD}$ and related dementias ( $\mathrm{z}$-score $=-3.004, \mathrm{p}=0.003)$ compared to their medical counterparts. The use of technology scored the lowest in both undergraduate training programmes whereas dealing with challenging behaviour scored the highest in BPharm students and second-highest in MD students (Table 2).

\section{Discussion}

The present study has shown that albeit the limited number of hours directed towards undergraduate dementia training, both final year medical and pharmacy students had adequate knowledge on AD with ADKS scores higher than US college students (8). However, analysis of ADKS subscales revealed that students following both undergraduate training programmes were unfamiliar with risk factors associated with the disease with a possible consequence of such students not being able to provide the required advice in terms of disease prevention upon graduation. Conversely, topics related to presenting symptoms and assessment and diagnosis were well recognised suggesting that they have the necessary skills to refer such patients to the appropriate support services for clinical assessment. However, whether such knowledge will eventually be translated into practice post-registration remains unclear. A recent national survey investigating practices in diagnosis, disclosure and pharmacotherapeutic management of dementia by general practitioners in Malta has found that referral to a dementia specialist was routinely adopted only by a limited number of practitioners (6). Interestingly, clinical placement played an important role in enhancing knowledge of risk factors, symptoms and treatment and management in pharmacy undergraduate students. It may be that learning through informal interaction with the care-recipient overcame any existing curriculum shortcomings and that hidden curricular activities can play a significant role in enhancing knowledge, shaping values and professional identity (10). A possible reason of why this has been observed in pharmacy and not medical students may lie in the different nature of their clinical placements. In MD students, these are mostly composed of ward rounds where students work in groups under the close guidance of medical specialists and with little hands-on experience. In addition, pharmacy students also attend pharmacy practice sessions designed to interact with clients on an individual basis thus enhancing the possibilty of building a closer relationship leading to a better understanding of their needs and concerns. As previously reported with undergraduate nursing students (9), medical and pharmacy undergraduates who had or cared for a family member with dementia were found to have higher scores in the caregiving subscale of the ADKS.

Closer analysis of the ADPM scores revealed that, similar to what has been reported with general practitioners (6), the majority of final year medical and pharmacy students believed that early pharmacotherapeutic management of $\mathrm{AD}$ could postpone institutionalisation. This is expected due to the strong national emphasis that early management and diagnosis of AD could prevent dependency onto long-term services (7). Only a minority of students (36.6\% MD; $47.8 \%$ BPharm) correctly indicated that AD pharmacotherapy does not stop the decline in activities of daily living. The observation that the lowest scores obtained for both undergraduate progammes $(23.2 \%$ MD; $25.6 \%$ BPharm) was to a question related to the efficacy to acetylcholinesterase inhibitors was strongly indicative of the lack of in-depth knowledge of how these pharmacotherapeutic agents work. Questions related to drug management in challenging behaviour also yielded low scores possibly reflecting on the limited training that medical and pharmacy undergraduate students receive in this field during their study programmes. This is of particular concern due to an increase risk of mortality and morbidity following the use of antipsychotic drugs in managing BPSD (11).

Compared to their medical counterparts, pharmacy students significantly valued the need of enhancing training that promotes interprofessional teamwork in the management of patients with $\mathrm{AD}$ and related dementias. There is a strong case of incorporating interprofessional education interventions in undergraduate medical and pharmacy dementia curricula as this has the potential of improving knowledge related to dementia recognition and care $(12,13)$. Notwithstanding the recent efforts by a number of national dementia plans together with individuals with dementia and their caregivers towards an increase in awareness and use of assistive technology (14), both medical and pharmacy students rated educational and training needs in this particular area as the least important. The lack of knowledge of how assitive technologies could support individuals with dementia may limit such healthcare professionals in providing advice on support systems that aim at enhancing autonomy, independence and quality of life.

In conclusion, this small scale study revealed that medical and pharmacy undergardaute training in the field of $\mathrm{AD}$ is not providing in-depth knoweldge and skills necessary to provide adequate care for these individuals. As a result, there is an urgent need to develop and implement pre-registration training modules designed to enhance the skills and better prepare the next generation medical and pharmacy professionals in the field of $\mathrm{AD}$ management and care. 
Acknowledgements: The authors would like to thank the students who participated in the study.

Conflict of interest: none

Funding: none

Ethical Standards: Ethical approval for the study was granted by the Faculty of Medicine and Surgery Ethics Committee and the Research Ethics Committee of the University of Malta.

\section{References}

1. Hofman A, Ott A, Breteler MMB et al. Atherosclerosis, apolipoprotein E, and prevalence of dementia and Alzheimer's disease in the Rotterdam Study. The Lancet 1997;349:151-154.

2. Scerri A, Scerri C. Dementia in Malta: new prevalence estimates and projected trends. Malta Med J 2012;24:21-24.

3. Tsolaki M, Papaliagkas V, Anogianakis G et al. Consensus statement on dementia education and training in Europe. J Nutr Health Aging 2010;14:131135.

4. StClair Tullo E, Gordon AL. Teaching and learning about dementia in UK medical schools: a national survey. BMC Geriatr 2013;13:29.

5. Oakley R, Pattinson J, Goldberg S et al. Equipping tomorrow's doctors for the patients of today. Age Ageing 2014;43:442-447.
6. Caruana-Pulpan O, Scerri C. Practices in diagnosis, disclosure and pharmacotherapeutic management of dementia by general practitioners - a national survey. Aging Ment Health 2014;18:179-186.

7. Scerri C. Empowering change: A national strategy for dementia in the Maltese islands. 2015. Parliamentary Secretariat for the Rights of Persons with Disability and Active Ageing, Valletta.

8. Carpenter BD, Balsis S, Otilingam PG et al. The Alzheimer's Disease Knowledge Scale: development and psychometric properties. Gerontologist 2009;49:236-247.

9. Scerri A, Scerri C. Nursing students' knowledge and attitudes towards dementia - a questionnaire survey. Nurse Educ Today 2013;33:962-968.

10. Annear MJ, Lea E, Lo A, Tierney L, Robinson A. Encountering aged care: a mixed methods investigation of medical students' clinical placement experiences. BMC Geriatr 2016;16:38.

11. Banerjee S. The use of antipsychotic medication for people with dementia: time for action. 2009. http:// www.rcpsych.ac.uk/pdf/Antipsychotic $\% 20$ Bannerjee\%20Report.pdf. Accessed 5 July 2016.

12. Brody AA, Galvin JE. A review of interprofessional dissemination and education interventions for recognizing and managing dementia. Gerontol Geriat Educ 2013; 34:225-256.

13. McCaffrey R, Tappen RM, Lichtstein DM, Friedland M. Interprofessioan education in community-based Alzheimer's disease diagnosis and treatment. J Interprof Care 2013;27:534-536.

14. Newton L, Dickinson C, Gibson G, Brittain K, Robinson L. Exploring the views of GPs, people with dementia and their carers on assistive technology: a qualitative study. BMJ Open 2016;13:6(5) 